Gas Kinetics

An Introduction to the Kinetics of Homogeneous Gas Reactions. By A. F. Trotman-Dickenson. Pp. $\mathrm{x}+322$. (London: Butterworths Scientific Publications; Now York: Academic Press, Inc., 1955.) $40 s$.

A NEW account of chemical kinetics by an active worker in the field is generally welcome, and the present volume is no exception to this. In his preface the author states that the book is written chiefly for undergraduates and for those beginning research. Almost inevitably the author's background and his desire for completeness render the treatment over-elaborate for the student and more suitable for the research worker, for whom the copious bibliography should be useful. Certain sections, such as that on transfer reactions, concern relatively new, expanding topics which would ènhance an undergraduate course and which are almost unavailable at 'text-book' level. The book deals largely with the author's interests and, although this leads to a certain bias, it has the advantage that much recent work is collected together for the first time, and the writing shows considerable freshness of approach.

Certain diagrams and tables are difficult to follow, partly because there is a tendency to include excessive detail ; and in some respects the text falls between two ideals. For example, in discussing Slater's theory, the reviewer feels that either a brief outline of the theory followed by its results should be given, or sufficient detail to enable the reader to work through an example for himself.

The general level of clarity of definition and readability is good, but occasionally, as in the allimportant first sentence of the introduction, the style is obscure. The book is stimulating, good value and it deserves to be read.

K. E. Howletw

Transistor Audio Amplifiers

By Richard F. Shea. Pp. xiii +219. (New York : John Wiley and Sons, Inc.; London : Chapman and Hall, Ltd., 1955.) 52s. net.

IUNCTION transistors are rapidly replacing therm-

ionic valves for audio-frequency amplification in many applications. Many circuit engineers with a particular interest in this topic will therefore be interested in this new book by R. F. Shea, which deals exclusively with it.

The book contains a mixture of theoretical and practical information. In common with most publications on transistors, it hinges on the use of 'equivalent networks'; one reason for this is that the internal feedback that occurs in transistors makes any other method of calculating their performance very difficult. It is a pity, however, that the author has not aaid more about the why and how of these networks before using them.

Almost a quarter of the book is devoted to listing manufacturers' data on a large number of American transistors. Scarcely any use is made of this material, which is, in any event, of little value in a book aimed at teaching fundamentals.

The book deals with the theory of the basic amplifier arrangements. It also has a chapter on preamplifiers where low noise and a reasonably high input resistance are required. Power amplifiers are discussed in some detail; in tho case of class $B$ circuits particularly, little is said about the relative merits of the verious arrangements or how they can best be driven. Finally, there is a useful chapter on the design of four practical amplifiers.
This book will probably find a place on the library shelves at establishments interested in transistor circuits. Some engineers may find it of sufficient value on some topics to acquire their own copies.

D. D. JONES

\section{An Introduction to Interferometry}

By Prof. S. Tolansky. Pp. viii $+223+5$ plates. (London: Longmans, Green and Co., Ltd., 1955.) $21 s$. net.

7 HIS book on interferometry sets an example that might well be followed in other branches of physics, for it is not often that an acknowledged authority sees fit to write a text-book on his own subject for ordinary-degree students. It is refreshing to read a work at this level written by an expert teacher who is, at the same time, completely familiar with the practical details of the experiments and instruments he describes.

The subject-matter is necessarily far more than could normally be included in a degree course, but those who have to teach physical optics will find the book a source of inspiration for the particular sections of interferometry with which they may wish to deal. A great variety of interferometers is included, with emphasis on practical detail and the particular uses to which they are put in practice. The theory is elementary, and no elaborate mathematics is used.

The excellence of the book is somewhat marred by evidence of careless and hurried writing. Some of the earlier diagrams are poor (for example, in Figs. 2.11 and 5.7 rays are shown passing through lenses without deviation, and in Fig. 4.6 reflected rays do not obey the law of reflexion); punctuation is sometimes incorrect, and there is constant use of the adverbs 'thus' and 'hence' as conjunctions. I hope that there will soon be a second edition in which all the diagrams and the text match the very high standard of the contents.

H. LIPSON

\section{The Mechanism of Evolution}

By W. H. Dowdeswell. (The Scholarship Series in Biology.) Pp. ix +99. (London: William Heinemann, Ltd., 1955.) $6 s$.

THE concept of evolution has revolutionized biological thought during the past century, yet its full significance tends to be missed in school science courses, leaving a prevailing impression of something vast and rather unreal, which took place in the remote past. Mr. Dowdeswell's remedy is to incorporate with the classical evidence an understanding of the ways in which small evolutionary changes going on now, in wild populations around us, can be studied experimentally. The fact that many such experiments could be undertaken by the schools themselves makes it all the more stimulating.

After a preliminary survey of the historical background, variation is described in the light of modern genetics. There follows a discussion of natural selection and the effects of such factors as population size, continuity or isolation upon it. Examples drawn from many fields, including the author's own researches, lend intense vitality to the account. In conclusion, practical advice is given on experimental studies, and there is a summary of the present status of evolutionary theory, followed by a glossary and bibliography.

The book should prove immensely useful not only to the sixth-form boys and girls for whom it is intended, but also to teachers and first-year university students.
MaUrice Ashby 